\title{
A CSCL Approach to Blended Learning in the Integration of Technology in Teaching
}

\author{
Dr. Michael Jones \\ University of Wollongong, Australia
}

mjones@uow.edu.au

\begin{abstract}
This paper presents a case study of a blended learning design where technology was integrated into a second year management subject in an attempt to increase student flexibility and interest while simultaneously delivering commercially valuable skills. Specifically, the study will evaluate the effectiveness of this move to a blended learning model of delivery and the use of social networking tools in aiding student learning. The technologies were designed to enhance the learning experience of students by providing an opportunity to work in small groups to collaborate on a group submission based on an authentic workplace scenario. Tasks were also designed to allow students to discuss their group project both synchronously, using a chat tool, and asynchronously, using discussions in the eLearning space. The success of this blended learning design is reported through analysis of the results from a student survey.
\end{abstract}

Keywords: Flexible learning, CSCL, ICT, Google Documents, Chat.

\section{Introduction}

Is there a way of engaging students that maintains their interest, provides a challenge, allows for personal flexibility, and still maintains academic standards and quality? Or to put it more simply, how can we provide a learning environment which is fun and appealing yet still meets the needs of a tertiary environment?

The summer session in our antipodean university collides with Christmas and New Year and, from a student perspective, with lots of drinking and partying, surfing, and fun. University is not a place students want to be during the Australian summer, especially when friends, who have not elected to sit through a voluntary summer session, are off doing things of much more personal appeal. Therefore, it is especially important during these times to create a learning environment which is still a pleasant place to be. I have found that rather than 'fight them' the best approach is to 'join them'. This paper will discuss the method I used, which provided student-teacher flexibility but was still consistent with delivery of the subject across all sessions through the year.

Material published as part of this publication, either on-line or in print, is copyrighted by the Informing Science Institute. Permission to make digital or paper copy of part or all of these works for personal or classroom use is granted without fee provided that the copies are not made or distributed for profit or commercial advantage AND that copies 1) bear this notice in full and 2) give the full citation on the first page. It is permissible to abstract these works so long as credit is given. To copy in all other cases or to republish or to post on a server or to redistribute to lists requires specific permission and payment of a fee. Contact Publisher@InformingScience.org to request redistribution permission.
The discussion that follows will cover the following sections: 1) in two parts the paper will discuss the teaching method used and the research approach adopted in this study, 2) literature which supports, or criticizes this approach to teaching will be discussed, 3) an argument will then extend to an analysis of the students response to this method, 4) a discussion will follow which will integrate the student responses, the course 
design and the literature, and 5) the conclusion, recommendations and lessons learnt will be presented which may help to guide others who may wish to pursue this teaching approach.

\section{The Teaching Method Used}

Due to the aforementioned impediments to the usually focused and, perhaps, conventional teaching environment, I decided to allow students to work off-campus as much as they could. While I converted one lecture into a virtual lecture using EduStream (an integration of voice and PowerPoint slides delivered via audio-stream), the main focus was to have students work together in a virtual environment from any location they wanted. The only caveat being, they must have access to a computer with a connection to the internet that was suitably fast and reliable. I selected three tools to assist in this process: Google Documents, Google Chat, and eLearning-Vista. Using this suite of tools, students were organized into teams to work together toward the completion of assessable projects. This integrated approach added to the flexibility of the subject allowing students to 'attend' classes in certain weeks without physically being on campus and to work with colleagues without sharing the same physical location.

The advantage of using these tools was clearly to provide the students with the flexibility they craved. There were, however, additional benefits. It was thought that this style of group work may more accurately reflect the real-world business environment they may eventually work in. This is due to the ubiquity of global organizations working across countries and time zones that are now using technology to facilitate communication and the sharing of knowledge (Kirschner, 2004). It would also simulate another real-world criterion; by having a very short deadline, students would experience a very strong sense of urgency

\section{The Task}

Students were randomly placed into groups of four or five people. In their first lecture, they were shown how to create a Google account through Gmail and how they can use Google Documents. Finally, they were given a homework task to collaborate with their team members using Google Chat and to send a Google Document to the coordinator with their team details, including their confirmed Google email address.

Three assessments and a practice session were created, each slightly more difficult than the one which preceded it. Each assessment was worth $10 \%$. These assessment tasks are listed in Table 1. The practice session was deliberately very simple so that students could concentrate on other elements of the task, especially their mastery of the technology and their ability to collaborate over the Internet using Google Docs and Google Chat. Following the practice session, more difficult academic tasks were assigned. These followed content that was covered in lectures. 
Table 1. Assessment Tasks

\begin{tabular}{|c|c|}
\hline Assessment & Task \\
\hline Practice Session & $\begin{array}{l}\text { The task will be to (as a group) find an example of a company which discusses personal values } \\
\text { (of employees) in their procedures or other corporate documentation. You are to write about } \\
\text { these findings using Google Documents and provide the evidence with correct citations and ref- } \\
\text { erencing. }\end{array}$ \\
\hline Assessment 1 & $\begin{array}{l}\text { Background: "Perception is a process by which individuals organize and interpret their sensory } \\
\text { impressions in order to give meaning to their environment" (Robbins, Judge, Millet, \& Jones, } \\
\text { 2010, p. 88). Many factors influence perception, and they have various effects on people and } \\
\text { work dynamics in an organization. } \\
\text { Your task: What are the various factors and influences associated with perception and what are } \\
\text { their effects in the organization? } \\
\text { Your team must: } \\
\text { 1. Select one perception type per team member. } \\
\text { 2. Explain - using literature - what the perception is, and how it works. } \\
\text { 3. Conduct research to find a real life example of this perception which illustrates the effect } \\
\text { it has in the workplace }\end{array}$ \\
\hline Assessment 2 & $\begin{array}{l}\text { Background: "A number of barriers can retard or distort effective communication" (Robbins et al } \\
\text { 2008, 378). These barriers can not only affect the actual communication, but can also disrupt } \\
\text { organizational harmony and cooperation. } \\
\text { Your task: In the lectures we discussed five broad categories of barriers: Physiological barriers, } \\
\text { Environmental barriers, Attitudinal barriers, Faulty assumptions, Socio-cultural differences } \\
\text { Your team must: } \\
\text { 1. Select one category of barrier per team member. } \\
\text { 2. Explain - using literature - what this category is and what types of barriers are com- } \\
\text { prised within it. } \\
\text { 3. Select one type of barrier within this category and conduct research to find a real life } \\
\text { example of this communication barrier which illustrates the effect it has in the work- } \\
\text { place. }\end{array}$ \\
\hline Assessment 3 & $\begin{array}{l}\text { Background: A strong organizational culture provides stability to an organization and has a posi- } \\
\text { tive impact on employee behavior. In a strong culture, the organization's core values are both } \\
\text { intensely held and widely shared and this combination works to provide a mutually beneficial } \\
\text { and value-optimizing environment. } \\
\text { Your task: The lectures emphasized six elements of a strong corporate culture: } \\
\text { 1. A widely-shared philosophy } \\
\text { 2. Concern for individuals } \\
\text { 3. Recognition of heroes } \\
\text { 4. Belief in ritual and ceremony } \\
\text { 5. Sense of informal rules \& expectations } \\
\text { 6. Belief that what employees do is important } \\
\text { Your team must: } \\
\text { 1. Select one element per team member. } \\
\text { 2. Explain - using literature - what this element is. } \\
\text { 3. Conduct research to find a real life company example of each selected element which il- } \\
\quad \text { lustrates the affect it has in the workplace }\end{array}$ \\
\hline $\begin{array}{l}\text { Additional } \\
\text { Instructions for } \\
\text { each assessment }\end{array}$ & $\begin{array}{l}\text { 4. Tie your essay/report together with: } \\
\text { A. An introduction, } \\
\text { B. A conclusion, } \\
\text { C. A cohesive argument, and } \\
\text { D. Appropriate references and referencing } \\
\text { REMEMBER - APPROX } 3 \text { PAGES - DOUBLE SPACED + introduction and conclusion }\end{array}$ \\
\hline
\end{tabular}

Teams were given three hours to complete the task, after which the electronic drop-box on eLearning-Vista would close, and they would receive zero marks. The first two hours were supervised by the tutor who had logged in as a member of the chat group and a contributor/editor of the Google document. While on line, the tutor would assess the quality of interaction and the use of the collaborative technologies. 
The assessment of these tasks (see Table 2) focused on three major areas. Half of the mark was allocated according the quality of the group's answer. A quarter was given for presentation of the answer, and the final 25\% was allocated for the group's use of the technology. To measure this last criterion the tutor would estimate the group's use (relative to other groups being monitored at the same time) of the online tools. These marking criteria were given to students prior to their engagement in activities and were balanced between an assessment of the artifacts produced and an assessment of teamwork (Ellis \& Hafner, 2008).

Table 2. Marking Criteria

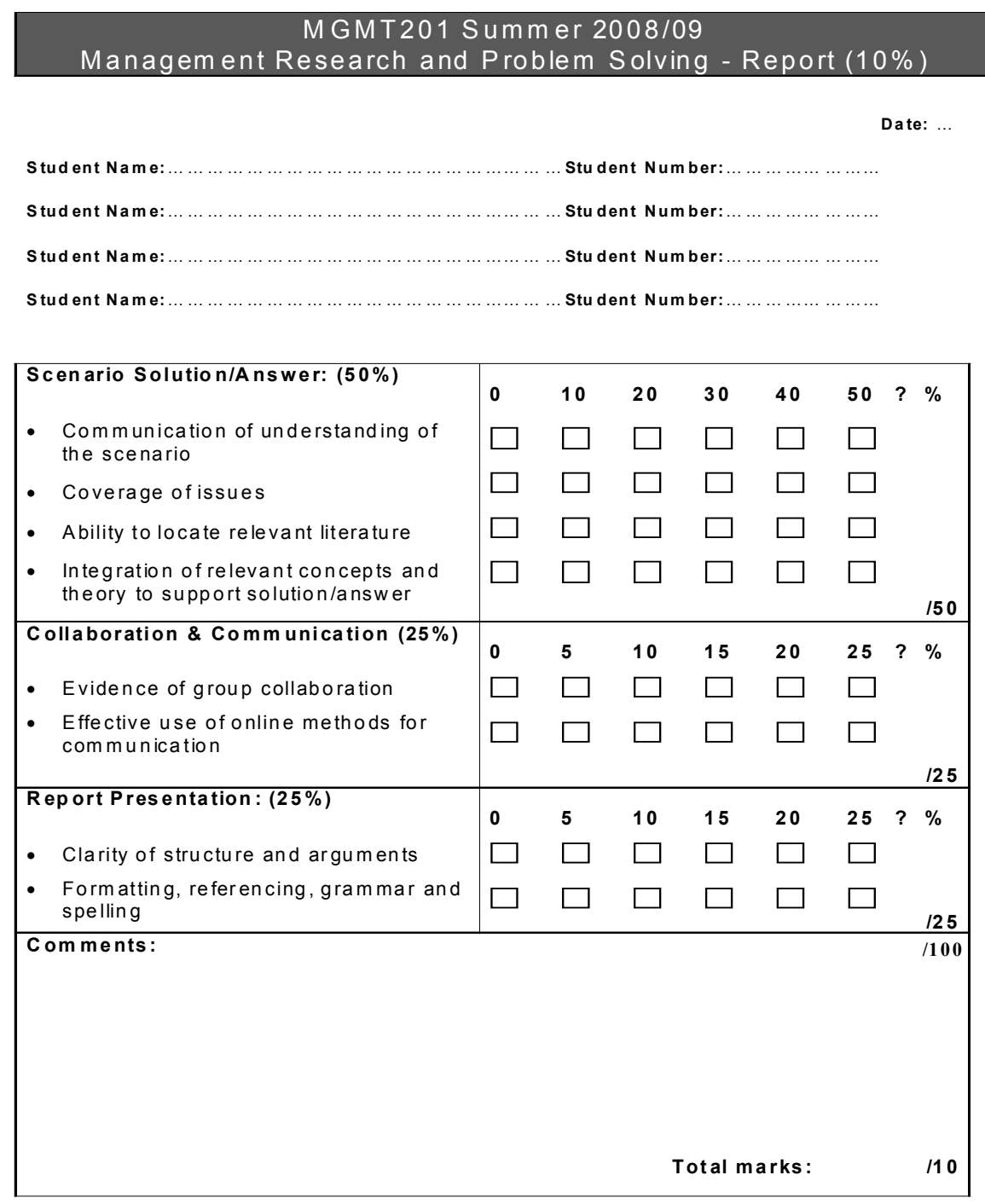

\section{The Research Approach}

A case study method was selected as a means of data collection, analysis, and discussion because it allows the researcher the opportunity of explaining the causal links in real-life situations that would be too complex for surveys or experimental strategies (Yin, 1989, p. 25). A case study is an empirical inquiry that "investigates a contemporary phenomenon within its real-life context; 
when the boundaries between phenomenon and context are clearly not evident; and in which multiple sources of evidence are used" (Yin, 1989, p. 27).

There are four general types of case study (see Table 3 ). These can be classified according to two dimensions: single or multiple case designs and holistic or embedded analysis. These are discussed below:

- Single-case design is the use of one case to explain or support a popular theory or hypothesis, because a single case is all that is needed to critically test the research question. This type of case study is analogous to a single experiment in science. Another reason for using a single-case design is in a situation where the researcher has an opportunity to observe a phenomenon or situation that is generally inaccessible to other forms of investigation, as in this case, for instance, with longitudinal participant observation.

- Multiple-case designs are usually a series of replications where the original design, often the pilot study, is repeated a number of times, sometimes with minor modifications. The study is usually designed so that results are either predictably similar, so that mutual support for a single conclusion is found (literal replication, or contrary results are predictably achieved (theoretical replication). If these results turn out as expected, the multiple-case design can be seen as providing evidence, which is compelling.

- Embedded analysis is where there is more than one unit of analysis, for instance where there are two or more individuals who will provide observational data to support the same hypothesis or theory.

- Holistic analysis is the opposite of embedded, where only the global nature of the study is considered. In this case there is little value in collecting data from various other sources. An analogy of these last two is to think of holistic analysis as a macro view and embedded analysis as a collection of micro views.

Table 3. Basic Types of Designs for Case Studies (Yin, 1989, p. 46)

\begin{tabular}{|l|c|c|}
\multirow{2}{*}{ Holistic (single unit of analysis) } & Single-Case Designs & Multiple-Case Designs \\
\cline { 2 - 3 } Embedded (multiple units of analysis) & Type 1 & Type 3 \\
\cline { 2 - 3 } & Type 2 & Type 4 \\
\cline { 2 - 3 } & &
\end{tabular}

Therefore, we have four types, resulting from differing combinations of these factors. The type used here is Type 1 - a single-case holistic design, as this type enables the study of one unit of analysis (this class) to support the one research theme, "How can we improve student attention through the integration of CSCL learning enhancements?"

\section{The Literature}

The type of learning undertaken in this project is commonly known as computer mediated collaboration, communication, and coordination (CM3C) or computer-supported collaborative learning (CSCL). This area of pedagogy focuses on group-based learning using computer mediated environments (Stahl, Koschmann, \& Suthers, 2006). CSCL emerged in the early 1990s through innovations arising from development of the internet. This technology enabled students to move from what were prescriptively isolating learning environments of a pre-internet world, to the more congenial collaborative environment of the World Wide Web. A major difference between CSCL and the ubiquitous electronic learning (eLearning) is that the former assumes an interactive stance, while eLearning works predominantly to deliver static material (PowerPoints, etc.) (Stahl 
et al., 2006). A second point of differentiation is the learning design and teacher interaction that takes place with CSCL. CSCL requires as much preparation, management, and involvement as would a regular face-to-face class (if not more). The benefit however, is that delivery can be asynchronous and remote (Díez, Fernández, \& Dodero, 2008; Kreijns, Kirschner, Jochems, \& van Buuren, 2004; Stahl et al., 2006). A final difference between CSCL and eLearning is that the former promotes interaction and collaborative learning between student participants. Students not only learn by doing, but also by seeing how other students learn and do. This extends a level of 'meaningful discourse' (Wishart \& Guy, 2009) to the learning activity, where knowledge is constructed from an integration of reflection, prior experience, and existing knowledge (Ellis \& Hafner, 2008). Ma (2009) extends this further through work by Engeström (1996) to the creation of 'communities of learning' with the augmentation of CSCL into the teaching curriculum.

Recent studies have found that CSCL enabled learning structures can improve the learning experience (de Bruyn, 2004; Dewiyanti, Brand-Gruwel, Jochems, \& Broers, 2007; Ewing \& Miller, 2002; Gilbert \& Dabbagh, 2005; Hewitt, 2003; Kanuka, Rourke, \& Laflamme, 2007; Resta \& Laferriere, 2007; Ma, 2009; Shellens \& Valcke, 2005; Wishart \& Guy, 2009) and can lead to "unprecedented learning outcomes" (Wishart \& Guy, 2009, p. 142).

The conventional model of learning comprises three criteria (Evensen, Hmelo, \& Hmelo-Silver, 2000):

1. Learning is a response to and recording of experience,

2. Learning is acknowledged as a change in behavior that occurs over time, and

3. Learning is a process that is not directly observable

CSCL moves away from this conventional learning process. CSCL disputes the final criteria of learning and sees learning as the construction of meaning that is created in a social space, organized through the mutual negotiation of the individuals as they collaborate (Kirschner, 2004). This area of learning theory - socially organized meaning construction - is informed by two areas of social theory: "social practice theory (Lave \& Wenger, 1991) and dialogical theories of learning (e.g., Hicks, 1996)" (Stahl et al., 2006, p. 9). The goal of learning through CSCL is to enhance the meaning-making of the group through the creation of artifacts and activities.

The design of CSCL activities must acknowledge the different learning environment and the varied expectations of its outcomes. Traditional pedagogy is not appropriate and may have the effect of alienating both students and staff. Task design should take into account three criteria: task ownership, task character, and task control (Kirschner, Strijbos, Kreijns \& Beers, 2004).

\section{Task Ownership}

Task ownership comprises three sub-criteria. Firstly, team members can be held as being individually accountable (IA). A degree of IA should ensure that each person carries his or her weight on a project. However, a strong reliance on IA can reduce social cohesion making individual components more important than the overall group effort. Secondly, positive interdependence (PoI) looks at the complementarity of group members along with group accountability. Tasks designed with high PoI will have a social element that builds cohesion, where individuals feel a sense of belonging. The team project in this case would have clearly identified roles for easy allocation according to member strengths. Thirdly, promotive interaction (PrI) should exist. PrI is where members of the group support and encourage each other in order to fulfill the requirements of the task (Kirschner et al., 2004). 


\section{Task Character (TCh)}

The character of the task is an important design consideration because it needs to match the nature of the social space where meaning-making will take place. Traditional tasks "are artificial in that they are usually very well structured, short in length, well defined, oriented toward the individual, and designed to best fit the content and not reality" (Kirschner et al., 2004, p. 55). The ideal task design for CSCL activities will involve "the use of realistic learning tasks consisting of a task description, an authentic environment to carry out the task, and cognitive feedback on the quality of the task performance" (Kirschner et al., 2004, p. 55). These real-life tasks are often best divided into individual components for individual group member consumption.

\section{Task Control (TCo)}

Task control is a measure of the degree of the autonomy that the learner has over his or her task, as far as content, pace, presentation, and other content variables. A high TCo permits the learner to direct his or her own learning task.

There is a clear need for more CSCL activities in academic learning. Universities are seeking more advanced means of achieving deep learning, understanding, and analysis. Universities and businesses are also making greater use of information communication technologies (ICT). CSCL is a means of inserting ICT competencies into curricula (Kirschner, 2004). Kirschner (2004, p. 40) states that businesses are increasingly looking for graduates with sophisticated skills above those generic skills provided by university. In particular, they are seeking individuals with 'transformative potential.' These individuals are equipped with skills that can extend above mere production and competitiveness to having the ability to transform their organization. New learning objectives should include:

- Shared realistic and relevant problems.

- Shared needs and goals.

- Room for multiple perspectives on the problems and their solutions.

- Shared responsibilities both for the process of achieving a final product and for the product itself.

- Mutual trust between the participants such that they are valued for their contributions and their initiative.

To gain these skills a different approach to education is needed. Through its virtual collaborative environment, CSCL is able to achieve this.

\section{Student Response}

Students were surveyed at the end of the subject and asked to compare the course changes to those of other subjects which, in general, were more conservative in their approach to design and assessment. An overwhelming majority $-83 \%$ - found that this mode of assessment was more convenient and more flexible, with students stating: "I can stay at home" and "MGMT201 fun and more freedom than others" and "... we were able to learn to complete assignments without coming to Uni, especially when there is other commitments due to the holiday season."

A large proportion of students (78\%) felt that the overall quality of the subject was improved as a result of the CSCL experience: "on-line assessments help us to improve our skills which is to finish an assessment in time" and "the online components were a nice and fresh idea which I think should show up in more commerce and management subjects."

When asked to compare the skills they learned to those they anticipated they would need when they leave university, $74 \%$ of the students felt they had gained valuable skills in the subject. However, the subject had a steep learning curve, which forced some students out of their comfort 
zones. When asked about their level of enjoyment of the subject, in comparison to other subjects, students were ambivalent with $39 \%$ being uncertain and only $43 \%$ feeling the subject was a definite improvement. However, there was a definite increase in enjoyment $(70 \%)$ when they compared the assessment tasks with their standard (essay-based) assessments: "Virtual was good. Stressful but good. It was completed in 3 hours."

Finally, individuals felt that the subject improved team-work and team relationships (70\%), but that the subject did not promote team equity in regard to shared workloads: "In virtual group assignments I believe it would be better to mark individually as I lost marks because other group members didn't contribute anything that related to the topic and added their work to the Google doc too late so that there was nothing, I could do about it. Also one person should not be responsible for ensuring other people do work correctly especially when there is only 3 hours to complete it."

Students communicated some criticisms of the subject. A large design issue rested on the problem of having adequate time for delivery. Subjects generally need to be delivered in a (2+1)x13 model, that is two hours of lecture, plus one hour of tutorial, each week for thirteen weeks, this equals 39 hours. The three virtual assessments and the virtual lecture (and a virtual multiple choice test delivered on-line) took up 18 of these hours. This left little time for the remaining lectures and tutorials, consequently, students and staff complained about the lack of face-to-face time: "Didn't find there was enough face to face time with lecturers." There were also complaints by students due to group issues, but these seem to be standard to any subject which assesses on group-work and weren't considered specifically relevant to this subject.

\section{Discussion}

The literature espouses three criteria for the design of CSCL activities. These three criteria can be broken into five elements necessary for the correct alignment of virtual activities to enhance learning. The first three regard task ownership: 1) individually accountable (IA), 2) positive interdependence $(\mathrm{PoI})$, and 3) promotive interaction (PrI). The fourth is: Task character (TCh), and the fifth: Task control (TCo). In the design of the current project each of these criteria can be evaluated. Table 4 shows this evaluation of design criteria

Table 4. Evaluation of design criteria

\begin{tabular}{|c|c|c|}
\hline Design Criterion & $\begin{array}{c}\text { Evaluation of current } \\
\text { subject design }\end{array}$ & $\begin{array}{c}\text { Potential impact on } \\
\text { subject outcomes }\end{array}$ \\
\hline Individually Accountable (IA) & Low & Poor \\
\hline Positive Interdependence (PoI) & High & Good \\
\hline Promotive Interaction (PrI) & High & Good \\
\hline Task Character (TCh) & High & Good \\
\hline Task Control (TCo) & Moderate & Poor \\
\hline
\end{tabular}

IA is considered to be low because teams were assessed as a group, and, although a team leader was assigned to encourage leadership and responsibility, no provision was made for individual achievement. The design could have moved to an individual assessment to improve this element of the design; however, the marking and supervision costs may have been prohibitive. PoI was high as students were encouraged to divide the tasks according to a complementary division of labor. This ensured that each individual had a chance to add value and contribute equitably. This was intended to build feelings of belonging and group membership. The nature of the task built 
high levels of PrI. This was mainly based on the urgency of the task with its highly stressful three-hour deadline. However, it also hinged on its increasing reliance on quality as each assignment built on the standards and expectations of the preceding assignment.

The tasks were designed (TCh) to provide a real-life task simulation. Students were not expected to trawl through dozens of journals to provide solutions to problems that were cloaked in academic jargon. Instead they were required to search for information and examples from real companies on the internet. Access to information was easy and instant. This approach is more likely to mimic the actual desk research they will be required to perform in industry. Task control (TCo) was limited in that tasks were prescriptive and little latitude was given for students to change the requirements of the task. The reason for this limitation was due to the need to retain consistency in marking the assessment across groups.

\section{Conclusion, Recommendations, and Lessons Learnt}

The subject was structured in line with design criteria outlined in the relevant CSCL literature. CSCL, it seems, provides a variety of student advantages including: increased collaboration, enhanced teamwork, and a greater student focus on deep learning, understanding, and analysis. The practice of CSCL techniques in the classroom also achieves a tactical insertion of ICT competencies into curricula and, thus, meets an important employment criterion for businesses.

Deployment of the revised subject went well. Students enjoyed the new approach and felt they learnt valuable skills which were more applicable to their expectations of needed skills in industry. The goal of providing flexibility, maintaining student interests, and developing challenging tasks was met and exceeded. In general, students praised the new approach. There were, however, criticisms. These were largely focused in two areas. Firstly, all of the new virtual tasks took time away from the reassurance of face-to-face teaching. While students enjoyed the flexibility, they felt they still needed a strong core of the conventional teaching approach. The virtual component was, therefore, not a suitable replacement for classroom-based learning. Secondly, students complained about group problems, and, while these seem to be the ubiquitous by-products of teambased learning, a better design may help to alleviate some of these problems. For instance, individual assessment may reduce the inequities, but this comes at a cost. The literature also points to the need for this with its discussion on Individual Accountability (IA).

Other problems students experienced were:

- Shortness of time and related stress. Students became better at managing time as the assessments progressed. However, the first assessment was a shock to most, and it resulted in large amounts of angst, generating many complaints.

The best strategy for managing this is to communicate the task constraints over and over again, and to make the trial assessment as real as possible.

- Inequities between the capabilities of members in their teams. This problem became more apparent as time progressed, usually because those students who were more capable adapted to the time/task constraints more quickly and rapidly became aware of skill shortages in their team.

The best way to manage this is to get teams to work out what each member does best (e.g., some are better at research, others are better at writing and compiling). They can then specialize in these areas and thus become more efficient.

On a final note I would recommend this approach for lecturers who wish to increase student engagement and flexibility, while at the same time developing skills in ICT. 


\section{References}

de Bruyn, L. (2004). Monitoring online communication: Can the development of convergence and social presence indicate an interactive learning environment? Distance Education, 25(1), 67-81.

Dewiyanti, S., Brand-Gruwel, S., Jochems, W., \& Broers, N. (2007). Students' experiences with collaborative learning in asynchronous computer-supported collaborative learning environments. Computers in Human Behaviour 23(1), 496-514.

Díez, D., Fernández, C., \& Dodero, J. M. (2008). A systems engineering analysis method for the development of reusable computer-supported learning systems. Interdisciplinary Journal of E-Learning and Learning Objects, 4(1), 243-257. Retrieved from http://www.ijello.org/Volume4/IJELLOv4p243257Diez.pdf

Ellis, T. J., \& Hafner, W. (2008). Building a framework to support project-based collaborative learning experiences in an asynchronous learning network. Interdisciplinary Journal of E-Learning and Learning Objects, 4(1), 167-190. Retrieved from http://www.ijello.org/Volume4/IJELLOv4p167190Ellis454.pdf

Engeström, Y. (1996). Developmental work research as educational research. Nordisk Pedagogik: Journal of Nordic Educational Research, 16, 131-143.

Evensen, D. H., Hmelo, C. E., \& Hmelo-Silver, C. E. (Eds.). (2000). Problem-based learning: A research perspective on learning interactions. Mahwah, NJ: L. Erlbaum Associates.

Ewing, J., \& Miller, D. (2002). A framework for evaluating computer supported collaborative learning. Educational Technology \& Society, 5(1), 112-118.

Gilbert, P., \& Dabbagh, N. (2005). How to structure online discussions for meaningful discourse: A case study. British Journal of Educational Technology, 36(1), 5-18.

Hewitt, J. (2003). How habitual online practices affect the development of asynchronous discussion threads. Journal of Educational Computing Research, 28(1), 31-45.

Kanuka, H., Rourke, L., \& Laflamme, E. (2007). The influence of instructional methods on the quality of online discussion. British Journal of Educational Technology, 38(2), 206-271.

Kirschner, P. (2004). Design, development, and implementation of electronic learning environments for collaborative learning. Educational Technology Research and Development, 52(3), 39-46.

Kirschner, P., Strijbos, J.-W., Kreijns, K., \& Beers, P. (2004). Designing electronic collaborative learning environments. Educational Technology Research and Development, 52(3), 47-66.

Kreijns, K., Kirschner, P. A., Jochems, W., \& van Buuren, H.. (2004). Determining sociability, social space, and social presence in (a)synchronous collaborative groups. CyberPsychology \& Behavior, 7(2), $155-172$.

Ma, A. W. W. (2009). Computer supported collaborative learning and higher order thinking skills: A case study of textile studies. Interdisciplinary Journal of E-Learning and Learning Objects, 5, 145-167. Retrieved from http://www.ijello.org/Volume5/IJELLOv5p145-167MA657.pdf

Resta, P., \& Laferriere, T. (2007). Technology in support of collaborative learning. Educational Psychology Review, 19(1), 65-83.

Robbins, S.R., Judge, T. A., Millet, B., \& Jones, M. L. (2010) Organisational behaviour - Essentials. Brisbane: Pearson.

Shellens, T., \& Valcke, M. (2005). Collaborative learning in asynchronous discussion groups: What about the impact on cognitive process? Computers in Human Behaviour, 21(6), 957-975.

Stahl, G., Koschmann, T., \& Suthers, D. (2006). Computer-supported collaborative learning: An historical perspective. Cambridge handbook of the learning sciences. 
Wishart, C., \& Guy, R. (2009). Analyzing responses, moves, and roles in online discussions. Interdisciplinary Journal of E-Learning and Learning Objects, 5(1), 129-144. Retrieved from http://www.ijello.org/Volume5/IJELLOv5p145-167MA657.pdf

Yin, R. K. (1989). Case study research - Design and methods. Newbury Park, CA, Sage.

\section{Biography}

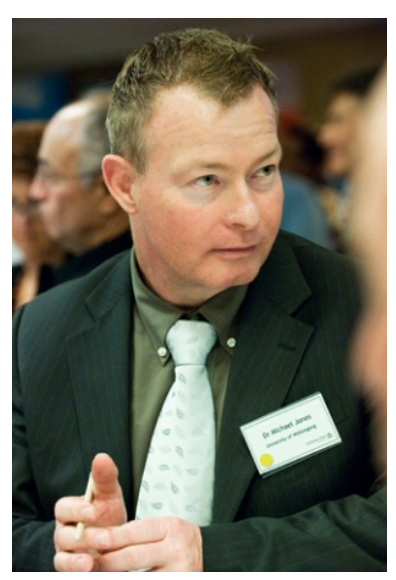

Michael Jones is a lecturer in Organizational Behavior in Australia's University of Wollongong. His recent writings focus on eCollaboration, especially with regard to small to medium enterprises. This has led to a number of competitive grants for research into this area. Early writings dealt with two principle areas; studies of qualitative methods, particularly in the field of grounded theory and computerized techniques for qualitative data analysis; and, organizational behavior, concentrating in areas of motivation and commitment. Michael received his $\mathrm{PhD}$ in organizational behavior from the University of Wollongong. 